\title{
Exploring the role of motivational and coping resources in a Special Forces selection process
}

\begin{tabular}{|c|c|}
\hline \multicolumn{2}{|c|}{$\begin{array}{l}\text { Authors: } \\
\text { Marié de Beer }{ }^{1} \\
\text { Adelai van Heerden }{ }^{2}\end{array}$} \\
\hline $\begin{array}{l}\text { Affiliations: } \\
{ }^{1} \text { Department o } \\
\text { and Organisati } \\
\text { Psychology, Un } \\
\text { South Africa, S }\end{array}$ & $\begin{array}{l}\text { f Industrial } \\
\text { onal } \\
\text { iversity of } \\
\text { outh Africa }\end{array}$ \\
\hline $\begin{array}{l}{ }^{2} \text { Behavioural S } \\
\text { Capability (Tec } \\
\text { Special Operat } \\
\text { for Scientific ar } \\
\text { Research, Sout }\end{array}$ & $\begin{array}{l}\text { ience } \\
\text { nology for } \\
\text { ons), Council } \\
\text { d Industrial } \\
\text { h Africa }\end{array}$ \\
\hline $\begin{array}{l}\text { Corresponden } \\
\text { Marié de Beer }\end{array}$ & ce to: \\
\hline $\begin{array}{l}\text { Email: } \\
\text { dbeerm@unisa }\end{array}$ & ac.za \\
\hline $\begin{array}{l}\text { Postal address } \\
\text { PO Box 392, Ur } \\
\text { South Africa OC } \\
\text { South Africa }\end{array}$ & iversity of \\
\hline $\begin{array}{l}\text { Dates: } \\
\text { Received: } 01 \mathrm{Ju} \\
\text { Accepted: } 25 \mathrm{~F} \\
\text { Published: } 21 \mathrm{~J}\end{array}$ & $\begin{array}{l}\text { ly } 2013 \\
\text { eb. } 2014 \\
\text { uly } 2014\end{array}$ \\
\hline $\begin{array}{l}\text { How to cite thi } \\
\text { De Beer, M., \& } \\
\text { A. (2014). Expl } \\
\text { of motivationa } \\
\text { resources in a } \\
\text { selection proce } \\
\text { of Industrial Ps } \\
\text { Tydskrif vir Beo } \\
40(1) \text {, Art. \#11 } \\
\text { http://dx.doi.o } \\
\text { sajip.v40i1.116 }\end{array}$ & $\begin{array}{l}\text { s article: } \\
\text { Van Heerden, } \\
\text { ring the role } \\
\text { and coping } \\
\text { special Forces } \\
\text { ss. SA Journal } \\
\text { ychology/SA } \\
\text { ryfsielkunde, } \\
55,13 \text { pages. } \\
\text { g/10.4102/ } \\
5\end{array}$ \\
\hline $\begin{array}{l}\text { Copyright: } \\
\text { (C) 2014. The A } \\
\text { Licensee: AOSI } \\
\text { OpenJournals. } \\
\text { is licensed und } \\
\text { Creative Comm } \\
\text { Attribution Lice }\end{array}$ & $\begin{array}{l}\text { Ithors. } \\
\text { This work } \\
\text { er the } \\
\text { ons } \\
\text { nse. }\end{array}$ \\
\hline 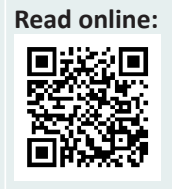 & $\begin{array}{l}\text { Scan this QR } \\
\text { code with your } \\
\text { smart phone or } \\
\text { mobile device } \\
\text { to read online. }\end{array}$ \\
\hline
\end{tabular}

Orientation: Motivational and coping resources were explored within a military context by means of a mixed-methods survey study involving a group of Special Forces candidates.

Research purpose: The purpose was to compare selected and not-selected candidates in terms of their sense of coherence, hardiness, locus of control and self-efficacy and to explore what they considered important for success in the selection process.

Motivation for the study: Because of high attrition rates in Special Forces selection, the evaluation of the role of motivation and coping resources in terms of possible predictive utility could benefit the organisation from a logistical, financial and efficiency point of view.

Research design, approach and method: A mixed-method cross-sectional survey design was used to assess an all-male candidate group $(N=73)$. The selected and not-selected groups were compared with regard to their sense of coherence, hardiness, locus of control and self-efficacy mean scores.

Main findings: No statistically significant differences were found between the mean scores of the two groups concerning the quantitative measures used.

Practical/managerial implications: The quantitative measures generally showed acceptable coefficient alpha reliabilities. Although no statistically significant mean differences were found between the groups, candidates showed high levels of sense of coherence, high levels of self-efficacy and average levels of hardiness and internal locus of control. The qualitative data confirmed the relevance of the quantitative constructs and pointed to additional aspects already considered in preparation for and during the selection process.

Contribution/value-add: The results provide information regarding the constructs and measures used in a military context.

\section{Introduction}

A career in the military, which is physically and psychologically more demanding than most civilian careers options (Skomorovsky \& Stevens, 2013), is often a lifestyle resolution as much as a career choice. The military context is particularly prone to stressors of a highly demanding nature such as physical exhaustion, exposure to climatic changes and prolonged absence from home. Furthermore, those serving in the military could face dangerous situations in which their own and others' lives are at stake (Bates et al., 2010; Cornum, Matthews \& Seligman, 2011; Skomorovsky \& Stevens, 2013). For those who are selected to serve in elite units such as the Special Forces, these demands and the risks associated with failure are particularly intense (Bartone, Roland, Picano \& Williams, 2008; Hunt, Orr \& Billing, 2013). Good general coping resources are therefore particularly important in the military context (Hobfoll et al., 1991; Maddi, 2013). Measurement and the use of constructs associated with coping resources could thus contribute to the management and improvement of wellbeing in the military (Cornum et al., 2011) by means of a focus on positive-psychology constructs such as hardiness, resilience and grit.

Positive psychology refers to the '... scientific study of what is "right about people" - as opposed to the traditional focus on the healing of psychological pain or trauma' (Molony \& Henwood, 2010, p. 15). Top military leaders have recognised the importance of psychological fitness (Casey, 2011) and that stress has a negative impact on performance. The US Army has therefore launched a large-scale project involving positive-psychology measures and training programmes (Cornum et al., 2011) in seeking to use the science of positive psychology to enhance resilience amongst the entire army community (Casey, 2011). The comprehensive soldier fitness (CSF) programme of the US Army is aimed at promoting wellbeing, developing psychological resilience and preventing problems by adopting a holistic, integrated, preventive and proactive approach (Casey, 2011; Cornum et al., 2011). Individuals with higher hardiness and better coping skills generally cope 
better with stressful circumstances and show fewer stress symptoms (Escolas, Pitts, Safer \& Bartone, 2013), These constructs can therefore be applied practically in the selection of military employees as those with higher coping resources are also likely to cope better with the stressors of the military context (Casey, 2011).

\section{Problem statement}

Stressors in the military context range from complex demands that integrate cognitive, physical, interpersonal and emotional aspects to possible life-threatening and dangerous situations. However, it also involves menial and repetitive tasks such as ensuring that military and personal equipment is clean and well maintained at all times and dealing with the frustration of long periods of low demand and boredom (Maddi, 2013). Emotional and psychological resources help with managing stressful situations when these are encountered (Gruber, Kilcullen \& Iso-Ahola, 2009) and are therefore also important for those working in the military context (Bates et al., 2010; Lee, Sudom \& McCreary, 2011).

Changing times, the diverse demographics of candidates and the new demands of modern-day warfare served as motivation for the exploration of the role of positive psychological constructs within the context of the South African National Defence Force (SANDF) Special Forces. This is in line with modern trends internationally where a number of wide-scale studies have been undertaken to evaluate the role of positive-psychology constructs within the broader military context (Seligman \& Fowler, 2011) as well as in the Special Forces context (Bartone et al., 2008). Due to the extreme physical and mental challenges that individuals in the Special Forces context often have to deal with, aspects such as physical and emotional resilience; physical, emotional and mental strength; grit; tenacity and perseverance have been the focus of a growing conversation around the profiling, screening and selection and training of these individuals (Bartone et al., 2008; Gruber et al. 2009; Hunt et al., 2013).

The Special Forces represent a specialised elite group within the military, and candidates are subjected to rigorous multifaceted selection procedures, representing extremely stressful conditions (Bartone et al., 2008; Hunt et al., 2013). Special Forces selection in South Africa represents a situation that is stressful at a physical, cognitive, emotional and interpersonal level - similar to elite military selection processes in other countries (Bartone et al., 2008; Hystad, Eid, Laberg \& Bartone 2011; Hunt et al., 2013). The selection process is specifically designed to be challenging on various levels as peak physical and mental performance during extremely stressful conditions is what the subsequent work context will demand (Bartone et al., 2008; Gruber et al., 2009; Hunt et al., 2013).

The selection process is known to have high fall-out rates with a high proportion of candidates starting with the selection process being unsuccessful - which adds to the logistical and financial burden on the military (Hunt et al.,
2013). It is therefore important to try to identify other factors that may help to lower the attrition rate. Candidates who participate in the Special Forces selection are physically prepared beforehand by means of a rigorous training program. According to Hunt et al. (2013, p. 623) nonphysical reasons for withdrawal or failure 'may lie in the candidate's cognitive and psychological state', and preventing potentially unsuccessful candidates from commencing with selection would lower the financial and logistical burden associated with the selection. It would also increase the success rate.

Special Forces members are expected to function in small groups, to be extremely adaptable and to withstand demanding and dangerous circumstances on a physiological, mental, interpersonal and emotional level whilst functioning in different cultural contexts (Bartone et al., 2008; Gruber et al., 2009), all of which represent stressors of different kinds. During the selection process, candidates are exposed to lack of sleep and extreme physical challenges in combination with constant pressure at individual and team level as well as constant monitoring of behaviour and performance (Maddi, Matthews, Kelly, Villarreal \& White, 2012). The present study was aimed at determining whether coping skills - in the form of a sense of coherence, hardiness, locus of control and selfefficacy - were significant factors in success or failure, given the extreme conditions of stress which the Special Forces selection process pose.

Considering both quantitative and qualitative data of the candidates involved in the selection process could contribute towards improved understanding of the psychological and other factors that contribute to success despite the highly stressful demands involved. Constructs such as sense of coherence, hardiness, internal locus of control and self-efficacy that have been associated with coping under stressful circumstances and challenges (Escolas et al., 2013; Maddi, 2013) could therefore also shed light on the factors that may contribute to success in the Special Forces selection process. Better insight into these factors within the particular context could be used to improve training and preparation or to improve or refine the selection and training programmes (Bartone et al., 2008) to help decrease attrition rates. The evaluation of the psychometric properties of these measures and comparisons of selected and not-selected candidates in a Special Forces selection process would provide information that could be used in this regard. Because of the high costs associated with the selection and training of elite soldiers (Gruber et al., 2009; Stark et al., 2011), reducing fall-outs and retaining those selected for the foreseeable future will optimise both cost and functionality within the military.

The selection process for the Special Forces within the SANDF includes assessment of physical, cognitive, motivational, personality and interpersonal aspects. Although the constructs considered can be linked to dimensions of positive-psychology constructs such as sense of coherence, hardiness, locus of control and self-efficacy, these have not been measured specifically or separately. The research question posed was the following: Do those who are selected 
differ significantly, as far as these constructs are concerned, from those who are not selected? Standardised measures for the different constructs were used to obtain the quantitative data to answer this question. From a qualitative perspective, the question posed was the following: What factors do candidates consider important for success in the selection process? The data obtained for this part of the study were the written responses provided by the candidates to an openended question on the factors they considered important in promoting or hindering success in the selection process. As a first step, the reliability values of the different positive psychology measures used were evaluated for this sample group. Secondly, the mean scores of the selected and notselected candidates on the different measures were compared to determine whether statistically significant differences were evident.

Due to the small size of the available sample, the MannWhitney non-parametric test was used to compare the mean scores of the selected and not-selected candidate groups (Field, 2009). The qualitative data was explored by means of content analysis, and the framework of dimensions and sub-dimensions of the quantitatively measured constructs was used to link the two datasets and to illustrate how the different quantitative constructs manifest - in the words of the candidates - within the particular selection context.

\section{Literature review}

The broad acceptance of the positive-psychology paradigm has been described as somewhat of a modern-day scientific revolution (Strümpfer, 1990) or at least a paradigm adjustment (Greenspoon \& Saklofske, 2000) in which a salutogenic (health-oriented) and fortugenic (strengthoriented) instead of a pathogenic (illness-oriented) view of individual functioning is taken (Strümpfer, 2006). The constructs of sense of coherence, hardiness, locus of control and self-efficacy were chosen as they have been associated with successful coping in stressful circumstances in general and in military contexts in particular (Antonovsky, 1987; Bandura, 2012; Bartone, Kelly \& Matthews, 2013; Escolas et al. 2013; Kobasa \& Pucetti, 1983; Maddi, 2013; Marais, 1997; Strümpfer, Eiselen, Meiring \& Phalatse, 2010).

\section{Sense of coherence}

Sense of coherence (SOC) is described as a global orientation that expresses a pervasive, enduring and dynamic confidence that stimuli and demands are structured and make cognitive sense; that resources are available so that stressors and demands are perceived as manageable and that the demands are worthy of investing or engaging with in a meaningful manner (Antonovsky 1993; Foureur, Besley, Butron, Yu \& Crisp, 2013; Sarenmalm, Browall, Presson, Fall-Dickson \& Gaston-Johansson 2013; Strümpfer, 1990). Individuals with higher scores on the construct(s) would have easier access to these resources and generally cope better with physical (i.e. sleep deprivation), mental (decision-making where failure could have catastrophic implications) and emotional (personally experiencing life-threatening situations) demands (Bartone et al. 2008; Gruber et al. 2009; Maddi, 2013).

Sense of coherence, according to Antonovsky (1987), comprises three dimensions, namely:

- Comprehensibility - being able to make cognitive sense of stressors.

- Manageability - perceiving resources as available to cope with the demands of the environment.

- Meaningfulness - believing challenges to be worthy of investment and engagement and being able to emotionally identify and commit effort to the handling of these demands.

Research on sense of coherence spans more than 30 years, and results support its utility and its being statistically significantly associated with performance (Strümpfer, Danana, Gouws \& Viviers, 1998), work engagement (Rothmann, Jorgensen \& Hill, 2011), work satisfaction (Strümpfer \& De Bruin, 2009), occupational stress (Van der Colff \& Rothmann, 2009) and burnout (Wiese, Rothmann \& Storm, 2003). Wong (2011, p. 74) suggested that 'without a sense of coherence, life is incomprehensible, unpredictable, and unsettling'. These sub-constructs and the overall main construct has been well researched internationally as well as in the South African context and is relevant for evaluating the coping profile of individuals who are required to perform in stressful work environments such as police officers, members of the special task force of the police and rescue-team members in mines (Bekwa \& De Beer, 2009; Strümpfer et al., 2010). In a military context, SOC has been associated positively with regard to psychosocial and risk factors (Ristkari et al. 2005), adjustment and lower posttraumatic stress disorder and depression (Luutonen, Sohlman, Salokangas, Lehtinen \& Dowrick, 2011) and thus seems to serve a protective function. This construct was therefore deemed important to include in the highstress, Special Forces, military context of the present research project.

\section{Hardiness}

High levels of hardiness are associated with strong commitment to life and work and enjoyment of new situations and challenges (Bartone et al. 2008). Some individuals are able to turn stressful life events into opportunities and possibilities for personal development (Kobasa \& Pucetti, 1983; Maddi, 2013). Such hardy individuals are able to set goals, make decisions and continue with other coping behaviour that they deem as important in life despite experiencing stressful life events. Those with higher scores on hardiness typically show good resilience, good health and high performance under stressful conditions and show a strong commitment to work and life whilst remaining actively engaged in work and other facets of their lives, creating their own sense of purpose and remaining motivated (Bartone et al. 2008).

Hardiness was extensively researched in a 12-year, longitudinal study involving the Illinois bell telephone (IBT) company where employees were tested each year for six 
years prior to and for another six years subsequent to a major deregulation of the industry which led to about $50 \%$ of staff being retrenched (Maddi, 2013). Whilst about two-thirds of the employees in the sample group did not cope with the forced changes - suffering from physical, emotional and social fallout symptoms, the other third showed surprising resilience - not only surviving but actually thriving in these stressful conditions (Maddi, 2013).

Research within the military context has shown hardiness to act as a stress buffer and to be a good long-term predictor of adaptability and performance of military leaders (Bartone et al. 2013).

Three sub-dimensional dispositions make up the overall hardiness construct:

- Commitment refers to actively involving oneself and showing curiosity in people, activities and things (Kobasa, Maddi, Pucetti \& Zola, 1985), which contributes to a general sense of purposiveness and engagement. Those strong in commitment believe that, however bad things get, it remains important to stay involved - rather than becoming detached and alienated (Maddi, 2013).

- Control refers to a belief in one's own influence rather than experiencing helplessness in the face of difficulties (Kobasa et al. 1985). Those high on control are convinced of the need to turn potential disasters into possible growth opportunities (Maddi, 2013).

- Challenge refers to individuals experiencing changes and responding to unexpected events as positive challenges rather than as threats - thereby showing an accepting, transformative, growth-oriented attitude rather than protective conserving or maintenance-oriented attitude towards challenges (Kobasa, Maddi \& Kahn, 1982). Those high on challenge are likely to see stressful changes as opportunities to grow (Maddi, 2013).

Hardiness has been hypothesised as protecting individuals from the effects of stress (Eschleman, Bowling \& Alarcon 2010). According to Maddi (2013), any two of the three subdimensions without the third one would limit hardiness whilst Bartone et al. (2013) showed that they can operate differently in terms of important outcomes. The total of these three scores provide an overall index of hardiness.

Hardiness was extensively researched in industry (Maddi 2013) and has also been applied in nursing (Hochwälder \& Forsell, 2011) and military contexts (Bartone et al. 2013; Maddi et al. 2012). With regard to the military application, hardiness significantly predicted admission into militaryofficer schools, with selected candidates in Norway obtaining significantly higher hardiness scores than nonselected candidates (Hystad et al. 2011). Hardiness has also been shown to predict in a statistically significant way the successful completion of military training - specifically in the Special Forces context (Bartone et al. 2008) and has predicted adaptability of military leaders in real-world contexts over time (Bartone et al. 2013). Results showed that hardiness scores of course graduates in the Special Forces are significantly higher compared to non-graduates - confirming hardiness to be 'an important construct associated with stress tolerance and successful performance in highly demanding occupations' (Bartone et al. 2008, p. 78). It therefore seems to be a potentially valuable personality style in Special Forces (Bartone et al. 2008) as it has been shown to be associated with greater psychological well-being and lower levels of stress (Skomorovsky \& Sudom, 2011).

Since hardiness is learned, hardiness training can enhance performance and decrease illness symptoms (Maddi \& Harvey, 2006). Therefore, if hardiness is shown to be a statistically significant predictor of selection and/or training results in the military and Special Forces context, programmes for hardiness training could be considered to better equip those exposed to the challenges of this context (Bartone et al. 2008). Hystad et al. (2011) recommended that research on hardiness should also be expanded to and replicated for multicultural groups.

\section{Locus of control}

Locus of control (Hunter \& Stewart, 2012; Rotter 1966, 1989) refers to the perception of situational control. The construct comprises two sub-dimensions:

- Internal locus of control refers to reinforcement and situational control being perceived as contingent upon own actions and under the individual's own control.

- External locus of control refers to reinforcement and situational control being perceived as not being entirely contingent upon the individual's own actions but rather seen as the result of or dependent on luck, chance, fate or powerful others.

According to Greenspoon and Saklofske (2000), an internal locus of control can help individuals to cope in demanding situations. The construct of locus of control is associated with an individual's motivational disposition as it reflects whether individuals perceive the outcome of events as contingent on their own behaviour or as being under the control of powerful others (Rotter, 1989). In the research by Al-Turkait and Ohaeri (2008, p. 939), individuals with an external locus of control showed significantly higher scores on psychopathology, anxiety, depression and avoidance compared to individuals with an internal locus of control, and in their view, contributed to 'the perpetuation of PTSD'. In a military context, locus of control has shown significant association with accident involvement (Hunter \& Stewart 2012). Locus of control has been found to be a good predictor of training and performance outcomes in a military context (Bradley \& Nicol, 2006). It was argued that participants with higher internal locus of control were more likely to hold views that their personal effort was directly linked to their performance (Bradley \& Nicol, 2006), which in turn may play a role in selection success. For this reason, this construct was included in the present study. 


\section{Self-efficacy}

Self-efficacy refers to how individuals judge their own capabilities, which in turn affect their motivation and behaviour by producing and regulating events in their lives to meet situational demands (Bandura 1982, 2012). It refers to individuals' belief in their capacity to mobilise resources on a cognitive level to take action and exercise control over task demands. These can in turn be seen as contributing to individuals' capacity to cope with stressors.

Empirical findings have shown that self-efficacy is negatively related to perceived stress and psychological distress (Gruber et al. 2009). Self-efficacy has been positively associated with motivation and performance by Chen, Gully and Eden (2001). According to Rimm and Jerusalem (1999), general self-efficacy relates to subjective confidence in mastering stressful demands. They further reported that 'a strong sense of personal efficacy is related to better health, higher achievement and more social integration' (Rimm \& Jerusalem 1999 , p. 329). Individuals with higher levels of self-efficacy are in general better able to deal with stressful demands and show better adjustment whilst those with lower levels of self-efficacy are likely to be more prone to self-doubt and anxiety when faced with stressful situations (Rimm \& Jerusalem, 1999).

Self-efficacy facilitates coping with stress from the early phases of cognitive appraisal of the stressors (Jerusalem 1992). In the military context, self-efficacy has been shown as a statistically significant predictor of successful completion of Special Forces assessment and selection (Gruber et al. 2009), providing support for its inclusion in this study.

The aim of the present study was to explore the utility of the positive-psychology constructs of sense of coherence, hardiness, locus of control and self-efficacy within the context of a Special Forces selection process involving very high physical, mental and emotional demands. In this regard, selected and not-selected individuals were compared on their mean scores of sense of coherence, hardiness, locus of control and self-efficacy to determine whether statistically significant differences were evident.

The research question posed with regard to the quantitative part of the research was: Are there statistically significant differences between the mean sense of coherence, hardiness, locus of control and self-efficacy scores of the selected and not-selected groups in a Special Forces selection context?

The hypothesis tested was:

Hypothesis 1: There are statistically significant differences between the mean scores of the selected and not-selected groups respectively concerning sense of coherence, hardiness, locus of control and self-efficacy.

A statistical significance level of .05 was chosen.

In terms of the qualitative part of the research, the questions posed before the start as well as after the completion of the selection process related to the factors and personal characteristics that candidates deemed important in helping or hindering their success during the Special Forces selection. These questions were aimed at exploring the factors that the candidates considered important to be successful in the Special Forces screening and selection process and whether these had any bearing on the constructs measured quantitatively. The project focus was on whether the combination of quantitative and qualitative data using a mixed-methods approach could lead to a better understanding of the chosen constructs within the specific context (Creswell \& Garrett, 2008).

\section{Research design}

A convergent, parallel, mixed-method, cross-sectional survey research design was deemed most appropriate to answer the research questions by allowing for both quantitative and qualitative data to be gathered during the limited time available (Creswell \& Plano Clark, 2011). This involved separate analyses of the quantitative and qualitative data and integration of the findings towards the end of the process.

\section{Research approach}

A mixed-methods approach was used with the aim of obtaining quantitative and qualitative data concurrently (Fetters, Curry \& Creswell, 2013) to explore the utility of the positive psychology constructs and measures that have been used with some success within the broader security domain (Bekwa \& De Beer, 2009; Strümpfer et al. 2010) as well as in other work domains locally (Gropp, Geldenhuys \& Visser 2007; Strümpfer \& De Bruin, 2009; Van der Colff \& Rothmann, 2009) and in the military (Escolas et al. 2013; Skomorovsky \& Stevens 2013). The inclusion of qualitative data allowed for confirmation and explication of the quantitative constructs concerned as well as for additional constructs or factors to be identified and considered.

\section{Research method Research participants}

The sample group consisted of a group of 73 male candidates between the ages of 19 and 29 years (mean age of 23.49 years) from different race and language groups who participated in a particular round of the Special Forces selection process. In light of the small available sample (which constituted the total population for the particular selection process - with resulting statistical limitations), the mixed-method approach was used to allow for qualitative data for the same sample group to be considered too. All candidates had to meet certain requirements concerning physical and mental ability to be included in this final selection process. Although candidates did not know exactly what the selection process would involve, they were well aware of the extreme physical, mental and emotional demands of the selection process.

The race distribution of the group is broadly representative of the South African population although white members are somewhat over-represented $(17.8 \%$ from the population representation of around $8.8 \%$ ) and members from the 
mixed-race community are somewhat under-represented (2.7\% from the population representation of 9\%) (Statistics South Africa [StatsSA], 2012). In the general population, people of Indian descent represent $2.6 \%$ of the population, and in this sample, there was no candidate of Indian descent. It was not expected that the spread of first languages of the candidates in this sample group would be representative of South African official languages. Except for English, which was over-represented, and isiZulu, which was underrepresented, most of the other languages were represented within $5 \%$ of their official proportion when one compares them to the official language distribution in South Africa based on the latest census information (StatsSA, 2012) (see Table 1).

All candidates in the applicant group met the minimum educational requirement of Grade 12 with a small percentage (16.9\%) having higher-level qualifications. On average, they had been employed by the SANDF for just over three years (3.25 years on average).

The relevant population consists of SANDF Special Forces soldiers, and although the current sample group could be considered reasonably similar to other groups involved in similar selection processes, their voluntary participation and the convenience sample that they represent limits broader generalisation from the current study.

\section{Measuring instruments}

Biographical information obtained is reported in Table 1. The study focused on four variables (sense-of-coherence, locus of control, hardiness and self-efficacy). The measures included for the quantitative part of the present study were the Orientation to Life Questionnaire (OLQ) of Antonovsky $(1987,1993)$ to measure sense of coherence, the Personal Values Scale Hardiness Questionnaire of Kobasa (1979), the

TABLE 1: Race distribution of the sample group.

\begin{tabular}{llll}
\hline Groups & Sample Frequency & Sample \% & $\begin{array}{l}\text { South African } \\
\text { Population } \\
\text { Statistics (\%) }\end{array}$ \\
\hline Race & & & \\
African & 58 & 79.5 & 79.6 \\
Mixed-race & 2 & 2.7 & 9 \\
Indian & 0 & 0 & 2.6 \\
White & 13 & 17.8 & 8.8 \\
Home Language & & & \\
Afrikaans & 11 & 15.07 & 13.45 \\
English & 14 & 19.18 & 9.60 \\
Ndebele & 0 & 0.00 & 2.14 \\
Sepedi & 9 & 12.33 & 9.06 \\
Sesotho & 6 & 8.22 & 7.55 \\
Siswati & 1 & 1.37 & 2.55 \\
Xitsonga & 1 & 1.37 & 4.47 \\
Setswana & 8 & 10.96 & 7.98 \\
Tshivenda & 1 & 1.37 & 2.37 \\
IsiXhosa & 13 & 17.81 & 16.00 \\
IsiZulu & 9 & 12.33 & 22.74 \\
Sign language & 0 & 0.0 & 0.46 \\
Other languages & 0 & 0.0 & 1.63 \\
\hline Total & 73 & 100 & 100 \\
\hline Source: Stics & & & \\
\hline
\end{tabular}

Source: Statistics South Africa. (2012). Census 2011 - statistical release (revised) P0301.4 Pretoria: Statistics South Africa. Retrieved April 6, 2013, from http://www.statssa.gov.za locus of control (LOC) measure of Rotter $(1966,1989)$ and two general self-efficacy Questionnaires (Chen et al. 2001; Rimm \& Jerusalem, 1999).

Measurement of sense of coherence: The 29-question version of the Orientation to Life Questionnaire (OLQ) of Antonovsky (1987) was used to measure the sense of coherence of the candidates. Sub-scores on comprehensibility (11 items), manageability (10 items) and meaningfulness (8 items) can be calculated with the sum of the three scores providing the overall sense of coherence score. Coefficient alpha reliability of the measure has been reported as ranging between 0.83 and 0.93 (Antonovsky, 1993).

The questionnaire was administered to measure the sense of coherence and the sub-dimensions of comprehensibility, manageability and meaningfulness of the available convenience sample group involved in a Special Forces selection process. This group was too small to allow for factor analysis and a decision was taken to use the standard questionnaire without any changes to allow for comparison with other published results - despite some researchers having questioned the quality of some of the items (Van Schalkwyk \& Rothmann, 2008).

Measurement of hardiness: Kobasa's (1979) 50-item Personal Values Scale (PVS) Questionnaire was used to measure hardiness. It comprises three sub-scales of commitment (15 items), control (17 items) and challenge (18 items) with the collated score reflecting overall hardiness. These statements are presented to participants to indicate the extent to which the possible answers ranging from zero (not at all true) to three (completely true) are applicable to the individual.

Hardiness has been reported as moderating stress with internal consistency reliability values ranging between 0.68 and 0.85 (Kobasa, 1979). The scoring was adjusted so that higher scores overall could be associated with a higher levels of hardiness.

Measurement of locus of control: Rotter's 29-question Locusof-Control Questionnaire was administered to the sample group in its original and standard form. Strümpfer (1990) reported coefficient alpha values of between .74 and .84 for various local studies. The scoring determines the external locus of control score, which is then used to determine the internal locus of control score as the scores always have to add up to a total of 23.

Measurement of self-efficacy: Two different self-efficacy questionnaires were included in this study, namely the New General Self-Efficacy Questionnaire (Chen et al. 2001) and the General Self-Efficacy Scale (Rimm \& Jerusalem 1999). The statements in these questionnaires are all positively phrased, so no reverse scoring was required.

The two questionnaires respectively consisted of:

- The eight-question New General Self-Efficacy Scale 
(NGSE) (Chen et al., 2001) rated on a five-point scale (strongly disagree, disagree, uncertain/undecided, agree to strongly agree).

- The ten-question General Self-Efficacy Scale (GSE) (Rimm \& Jerusalem, 1999), which uses a four-point scale (not at all true; hardly true; moderately true; exactly true), showing internal coefficient alpha reliability of between 0.75 and 0.91 (Rimm \& Jerusalem, 1999).

Qualitative data gathering: For the qualitative component of the study, the researchers wanted to explore what the candidates deemed important for success in the selection process and to reflect on and elucidate the degree of alignment of the qualitative content to the quantitative constructs measured. Open-ended questions were included when the paper-and-pencil questionnaires were completed and were posed in written format and required written responses from participants the day before as well as after completing the screening and selection process.

\section{Research procedure and ethical considerations}

The current project forms part of a larger research project initiated and managed by the Special Operations Defence Evaluations and Research Institute (SODERI) and the Technology for Special Operations Division of the Council for Scientific and Industrial Research (CSIR). Ethical approval was obtained from relevant bodies responsible for overseeing research within the military context. Consent for data gathering was also obtained from the commanding officer responsible for overseeing the selection process. In addition to institutional permission for the project, individual informed consent was obtained and confidentiality was assured. Participants were informed of the aims of the project and assured that their anonymity would be protected and that their results would be securely stored. They were informed that their participation in the research was voluntary and that they could choose not to complete the questions and statements, with no negative consequence to them in respect of the selection process in which they were participating. Each participant signed consent forms for the survey process preceding and upon completion of the selection process.
After voluntarily agreeing to participate and after signing a consent form, participants completed the questionnaires. Although none of the candidates withdrew on a voluntary basis, there were some who did not complete the openended questions, and there was also some missing data in the quantitative sections of the questionnaire. This accounts for varying sample sizes in the reporting of the results. The quantitative and qualitative responses to the questionnaires were captured for further statistical and qualitative analysis. Numbers instead of identifiable personal detail were used to identify participants, and files were protected with passwords.

The questionnaire administered to the candidate group before commencing with the selection process contained a consent form, biographical questionnaire, the quantitative measures and the open-ended questions. A similar process of informing participants of their rights, signing of consent forms and obtaining their willing participation in the research was followed on completion of the selection process. At that stage, the participants knew whether or not they had been successful. During this second phase of data gathering, only biographical and open-ended questions were posed.

\section{Data analysis}

Quantitative data analysis: The quantitative data analysis was performed using SPSS Version 20. It comprised descriptive analysis for the results obtained on the different measuring instruments with reverse coding as per the instructions for the scoring of the specific questionnaires. Cronbach coefficient alpha internal-consistency reliability scores were determined for all the available constructs and their sub-dimensions and are reported for the total group in Table 2 .

The Kolmogorov-Smirnov and Shapiro-Wilk tests (Field 2009) were used to test the normality of the distribution of the variables, and based on the mixed results and the small sample size, the non-parametric Mann-Whitney $U$ test for comparing the mean scores of independent samples was used to compare the mean scores of the selected and not-selected groups on the different variables (Field, 2009). Statistical

TABLE 2: Quantitative results for the total sample group and for the comparison of the selected $(N=16)$ and the not-selected $(N=57)$ groups.

\begin{tabular}{|c|c|c|c|c|c|c|c|c|c|c|c|c|c|}
\hline \multirow[t]{2}{*}{ Measure } & \multirow{2}{*}{$\begin{array}{l}\text { Number of } \\
\text { items }\end{array}$} & \multicolumn{4}{|c|}{ Total Group $(N=73)$} & \multicolumn{3}{|c|}{ Selected Group $(N=16)$} & \multicolumn{3}{|c|}{ Not-Selected Group $(N=57)$} & \multirow{2}{*}{$\begin{array}{c}\begin{array}{c}\text { Mann-Whitney } \\
\text { U-Test }\end{array} \\
\text { Significance }\end{array}$} & \multirow{2}{*}{$\begin{array}{c}\text { Effect Size } \\
r_{\dagger}^{\dagger}\end{array}$} \\
\hline & & $N$ & $M$ & SD & $\alpha$ & $N$ & $M$ & SD & $N$ & $M$ & SD & & \\
\hline SOC Comprehensibility & 11 & 70 & 57.56 & 12.748 & .841 & 16 & 56.13 & 12.633 & 54 & 57.98 & 12.869 & .502 & .008 \\
\hline SOC Meaningfulness & 8 & 72 & 50.26 & 7.558 & .798 & 16 & 51.19 & 6.025 & 56 & 50.00 & 7.970 & .556 & .069 \\
\hline SOC Total score & 29 & 68 & 167.53 & 26.036 & .916 & 16 & 167.00 & 23.332 & 52 & 167.69 & 27.025 & .675 & .049 \\
\hline Hardiness commitment & 15 & 66 & 36.17 & 5.170 & .676 & 15 & 35.27 & 4.652 & 51 & 36.43 & 5.326 & .334 & .113 \\
\hline Hardiness challenge & 18 & 64 & 28.53 & 5.965 & .607 & 14 & 28.29 & 6.318 & 50 & 28.60 & 5.928 & .714 & .043 \\
\hline Hardiness total score & 50 & 54 & 102.31 & 13.389 & .806 & 13 & 101.31 & 15.212 & 41 & 102.63 & 12.949 & .537 & .072 \\
\hline LOC External & 23 & 66 & 8.39 & 2.903 & .505 & 16 & 8.19 & 2.639 & 50 & 8.46 & 3.005 & .769 & .034 \\
\hline LOC Internal & (23) & 66 & 14.61 & 2.903 & $(.505)$ & 16 & 14.81 & 2.639 & 50 & 14.54 & 3.005 & .769 & .034 \\
\hline New general self-efficacy & 8 & 73 & 36.88 & 2.764 & .823 & 16 & 37.25 & 2.793 & 57 & 36.77 & 2.771 & .500 & .079 \\
\hline General self-efficacy & 10 & 72 & 35.33 & 3.958 & .838 & 16 & 36.06 & 3.924 & 56 & 35.13 & 3.977 & .365 & .106 \\
\hline
\end{tabular}

LOC, locus of control; SOC, sense of coherence; M, mean; SD, standard deviation; $\alpha$, alpha

$\dagger$, effect size $r=\mathrm{z} / \mathrm{VN}$ 
comparisons of the mean scores for the selected and the not-selected groups were done for the different dimensions and sub-dimensions and are also reported in Table 2 with inclusion of $r$-values for effect sizes (Cohen, 1992).

Qualitative data analysis: The qualitative data obtained by means of written responses to open-ended questions prior to and on completion of the selection process were captured electronically and analysed by means of thematic content analysis (Terre Blanche, Durrheim \& Kelly, 2009). The written responses of candidates to the questions about what they considered most important in either helping or hindering success in the selection process were used as data to explore how the constructs measured quantitatively manifest in the data (Braun \& Clarke, 2006). The written responses were generally short. The first phase of familiarisation and immersion (Braun \& Clarke, 2006; Terre Blanche et al. 2009) was followed by coding, identifying, reviewing and, where appropriate, naming themes in line with the framework provided by the quantitative constructs and their subdimensions.

Braun and Clarke (2006, p. 4, 6) referred to thematic analysis as 'a foundational method for qualitative analysis' for reporting 'patterns (themes) within data'. The data was read several times in order to understand the whole, and codes were labelled (primarily, though not exclusively) in line with the relevant dimensions and sub-dimensions that were measured quantitatively. Codes were grouped into broader themes in a further attempt to generate deeper understanding of the candidates' experiences (Johnson \& Waterfield 2004). From the perspective of essentialism or realist thematic analysis 'which reports the experiences, meaning and reality of the participants' (Braun \& Clarke 2006, p. 9), a process of mapping a framework onto qualitative descriptions (Griffiths, Ryan \& Foster, 2011) was followed from the theoretical position of the positive-psychology constructs used in the quantitative measurement with the aim to provide a more detailed explication of the constructs involved. The codes and identified themes were reviewed by the second researcher, and they were discussed and revised with the aim of 'confirmability' and peer review of themes emerging from the data rather than 'verification' (Graneheim \& Londman 2003, p. 110; Johnson \& Waterfield, 2004).

Whilst the definitions of the constructs and their subdimensions were used to form a basic framework for coding and eliciting themes, thematic analysis was not restricted to these. Codes and themes outside of this framework were also noted.

\section{Results}

Results for the Kolmogorov-Smirnov and Shapiro-Wilk normal distribution tests (Field, 2009) were mixed with comprehensibility, commitment, challenge, hardiness (total score) and locus-of-control scores normally distributed and other variables not normally distributed. Considering the small sample size and the mixed results for the tests for normal distribution, a decision was taken to use the nonparametric Mann-Whitney U test for comparison of the mean scores of independent samples (Field, 2009).

With the exception of the locus-of-control measure, acceptable coefficient alpha reliability values were found for all the other standardised quantitative measures - indicating that they could be considered for use within the military and Special Forces contexts. Reliability evidence is, however, a first step only, and evidence in support of validity need to be obtained in time when data from different samples can be collated to increase the available sample size. The descriptive results for the different measures are reported in their standard scales for comparison with other reported research results.

Descriptive results: In terms of sense of coherence, the overall mean score was 167.53 (SD 26.04) whilst the different sub-score means for this sample group were as follows: comprehensibility mean score: 57.56, SD 12.75; manageability mean score: 59.51, SD 9.45 and meaningfulness mean score: 50.26 , SD 7.56 .

The hardiness mean total score (102.31, SD 13.39) and the internal locus of control mean score of 14.61 (SD 2.90) were higher than the mean external locus of control score of 8.39 (SD 2.90), but low reliability of this measure precludes the use and interpretation of these scores.

The general self-efficacy mean score on the GSE for the current group was 35.33 (SD 3.96) whilst the mean score for the NGSE scale was 36.88 (SD 2.76) (see Table 2).

\section{Comparison of mean scores of the selected and not-selected sub-groups}

Following the evaluation of the internal consistency reliability scores for the different measures and the descriptive values for the total sample group, Mann-Whitney $U$ test analysis for comparing the mean scores of the selected and the nonselected groups were conducted for all the different scores (Field 2009). The results of the statistical comparison of the mean scores of the two groups for all the scales are reported in Table 2. It should be kept in mind that, due to low internal consistency reliability, the internal and external locus of control scores are reported but will not be interpreted for the current group. These results address the research question that was posed, namely whether statistically significant differences would be found between the selected and the not-selected candidate groups with regard to the different quantitative measures obtained. No statistically significant differences were found between the two groups on any of the positive psychology measures used. The research hypothesis is therefore refuted.

\section{Qualitative data analysis results}

Thematic content analysis of the qualitative data (Braun \& Clarke, 2006; Terre Blanche et al. 2009) was followed by a process of mapping the content onto the framework of the positive-psychology constructs used in the present 
study (Griffiths et al. 2011). The aim was to obtain a deeper understanding of how the positive-psychology constructs would apply to and manifest within the particular context when mapped onto the descriptions provided by Special Forces candidates in terms of what they deemed important for facing up to the challenges of and achieving success in the selection. The convergent design process described by Cresswell and Plano Clark (2011) was followed in that, after an initial independent analysis, the quantitative and qualitative data were compared across the dimensions measured quantitatively. In some cases, the qualitative data went beyond these dimensions. The quantitative and qualitative data were aligned, where appropriate, and integrated, refined and interpreted.
The qualitative data, analysis, results and interpretation were peer reviewed by the second researcher. The main themes extracted and alignments made to the theoretical framework were confirmed. Additional themes outside of the original framework identified by the second researcher were discussed and incorporated.

The thematic content analysis emphasised the overlap of the qualitative data with the quantitative constructs measured (see Table 3).

Additional themes identified outside of the framework of positive-psychology constructs covered by the quantitative measures were the level of motivation ('it's a very tough

TABLE 3: Thematic content analysis mapping onto the quantitatively measured constructs.

\section{Positive psychological construct descriptions}

Sense of coherence - Total: The global life view of understanding and being capable of being committed to dealing with life demands

Sense of coherence - Comprehensibility: Being able to make cognitive sense of demands

Sense of coherence - Manageability: Having at one's disposal (directly or indirectly) the resources to address demands

Sense of coherence - Meaningfulness: Being able to make sense of so as to commit to the demands

Hardiness - Total: Being able to turn stressful life events into opportunities and possibilities for personal development

Hardiness - Commitment: Remaining actively and purposefully involved in current challenges
Illustrative text $\dagger$

'Exactly knowing what the job entails and preparing according to it'

'Determination to succeed and become succesful in life, to be albe to take care of a family and gain maturity to be responsible in life'

'Mental readiness, people are fit but are not ready mentally so I think that is important.'

'Mentally you must come here ready and determined.'

'Mentaly strong - because most of the time you work under pressure'

'Physically and mentally prepared and being commited to your expectations' 'you must be confident that you will succeed in anything you do'

'One's mindset, determination and mental fitness'

'success goes with mental possetiveness and self motivation'

"Success goes with mental possetiveness and self motivation"

'You will be able to be at the right time and at the right place so that you can perform your duties in time and deligently and proffesionally'

'be able to work under any circumstances day or night because you will be you will be a specialising person 'be able to work under any circumstances

'I now have an idea of what a SF selection is like, so I wil definetely use this experience for my next selection' 'endurance, motivaiton, positive attitude, coping with stress'

'When everyone give up you must carry on'

'Endurance - being strong and positive when your fired and caring on even if there is an obstacle in front of you'

'My not passing selection was due to the fact that I lost focus at a critical stage' 'my ultimate goal to succeed and my drive to make it'

'Determinination - because even though it will be tough the fact that I know what I want will drive me to success'

'never loose focus no matter what happens'

'Mindset - because even if one's fitness level is of high standard but if the mindset is not correct nothing posititve can be achieved'

'Selection is al about being patient and knowing what you want in life and commitment'

'The most important thing htat helped me was my mind set, if your attitude is right nothing can stop you' 'Determination would also have played big role due to the fact of me knowing what I want'

'Mental preparedness - you have to be mentally strong to undergo all of challenges and to have the will and determination to keep going. it is important so that you can take on anything that comes your way' 'Endurance is the most important factor cause you must be able to take what come your way' 'but it does require mental fitness and always be posititve with everything you do' 'You must be willing to keep going event when you feel you cannot'

'Mentaly strong - u need to overcome most of things mental after you are tired'

'To be honest I underestimated the selection and that could have been my fault'

'You must have focus of why you wanted to do the selection in the first place no matter how tough it gets.'

'I just simply did not want to continue. I felt this way a few weeks before, but thought that I would be able to motivate myself. Unfortunately I could not seem to motivate myself. I just didn't want it anymore.'

'I did not reach the objective in the required time'

'if you can not motivate yourself or be a self-starter, then this is probably not the right environmetn for you'

"If you can not motivate yourselfor b

'I believe God has another plan for me'

'I didn't make the time cause the weather was not favourable it was very hot.'

'Really this is in important one, you must be inspired by someone or something to pass selection'

'Weather plays a role, it can make selection very difficult'

'Temperature - it influence the time you would usually complete an acersice [sic] under favourable conditions'

'Terrain - because is uneven and rocky and has a lot of uphills walking at knight [sic] cause a lot of injuries.'

'time was to little for me to make it'

'I could not handle the heat very well as it was contributin got the way in the walk (distance and timings) The terrain was killing my legs'

'I say God is everything, without him such things are impossible to make it till the end'

'I also have my reasons to succeed which i beleive will help me emotianally and last but not least, my faith

in God. i trust him wholeheartedly and believe that he will protect me and see me trhough because He want the best for me'

'the man that wants it most wil be the man that is succesful'

'Believing in yourself is another aspect that influences ones performance'

"how bad do you really want this? If you can convince yourself that its all worht the squeeze and that you really want this you will make it'

'Having no doubt about myself' resources to meet situational demands 
job and without the right motivation you will not succeed'; 'if you cannot motivate yourself, you will never make it'), teamwork ('to work as a team (unity) even in difficulties'; 'mainly it was about endurance and dedication to the team'; 'you have to be trustworthy so that your comrades can have confidence in your abilities'), physical ability ('I believed that I could get through it on pure physical strength but was sadly mistaken'), religion ('I believe it was God's will that I participated in selection. However God may open the door for you to selection, but He can't walk the kilometres or carry the big bag for you. He opened the door, I simply lacked the motivation to walk through it'; 'I knew what I wanted and mostly trusting in God') and environmental factors ('weather is the most important especially for the first exercise, it is hot'; 'weather conditions - it is important to be adaptable to the weather conditions of that place because if you are not you might encounter problems like dehydration').

\section{Integration of quantitative and qualitative results}

The qualitative data was to some degree limited in that the written responses to the questions were often cryptic - and the written format used for these responses did not allow for further probing. The themes extracted from the qualitative data available, generally showed alignment with the constructs measured in the quantitative part of the study when mapped on the framework of the measured constructs (see Table 3). Some additional themes - motivation, teamwork and physical ability - which have already been assessed within the selection process and some which have not - religion and environmental factors - were identified.

As displayed in Table 3, the personal descriptions provided in the qualitative part of the study illuminate how the real experiences and perceptions of the participating candidates embody the quantitative constructs within the Special Forces selection context.

\section{Discussion}

The results provide supportive reliability information for most of the measures used (except for the locus-of-control measure). The current sample size and available information did not include data to evaluate the validity of these measures.

From the perspective of the current study, the lack of statistically significant differences on all of the standardised measures between the selected and non-selected groups was unexpected as these results were contrary to other local and international results in which statistically significant differences were found between other contrast groups (selected and not-selected individuals and individuals working in normal versus more stressful circumstances within similar contexts (Hystad et al. 2011; Strümpfer et al. 2010). One possible reason could be that the entire group went through a 12-week preparatory phase during which they were guided and trained to prepare themselves both physically and psychologically for the selection process. The intensity and duration of the preparation just prior to the selection process may have resulted in more homogeneity in the total group with regard to these self-report scores. Furthermore, these candidates were all applying to work in the same stressful context and could be more similar than groups who work in different contexts.

The sense-of-coherence scores for this group (mean 167.53) were higher than the scores reported for any other South African samples that used the same measure. Some of the higher mean sense-of-coherence scores reported in other studies were $156.74(N=200)$ for a group of managers (Cilliers \& Coetzee, 2003), $154.48(N=434)$ for a group of police trainees (Bekwa \& De Beer, 2009) and $157.7(N=33)$ and $150.62(N=42)$ respectively for a group of Proto-team members in a mine and a group of Police Task Force members (Strümpfer et al. 2010).

The hardiness mean total score (mean 102.31) was slightly lower than that of a group of senior managers (mean 108.03, $\mathrm{SD} 13.88, N=39$ ) reported on when the Kobasa hardiness measure was used (Marais 1997).

The general self-efficacy mean score on the GSE for the current group (mean 35.33) was slightly higher than that reported for a local group of students (mean 30.39; $N=550$, reported in Wissing \& Van Eeden 2002) and an international study (mean 27.2; $N=670$ ) (Rimm \& Jerusalem 1999).

In terms of the sense-of-coherence results in particular, it would imply that the current sample group of candidates in general:

- Would be able to perceive stressful stimuli as making sense, as being ordered, consistent, structured and clear - as opposed to being chaotic, disordered, random, accidental and unpredictable (comprehensibility).

- Would have strong views that they had the required resources available to meet the demands of set stressors by resources under their own control or the control of legitimate or accessible others (manageability).

- Could make sense of the stressors, thereby contributing to their sense of being able to commit to extending the required actions necessary to cope with the demands (meaningfulness).

- Would generally be able to cope with stressors (general sense-of-coherence).

In terms of self-efficacy, their scores indicate that they would generally feel confident in their own abilities and believe that their own behaviour will determine outcomes. Practically, this would translate to them having the belief in their capacity to mobilise resources on a cognitive level to take action and exercise control over task demands which would contribute to their ability to cope with stress (Rimm \& Jerusalem, 1999; Wissing \& Van Eeden, 2002).

These results seem to indicate that candidates who present themselves for the Special Forces selection process show 
profiles high in general coping and self-belief and average in terms of hardiness. It should be kept in mind that these candidates had undergone a lengthy preparation period prior to the selection process and that the measures used in the current study were all of a self-report nature.

The themes extracted from the qualitative data analysis clearly demonstrate alignment with the quantitative constructs and emphasise the importance of general motivational and coping resources to deal with the cognitive, emotional and physical demands encountered in the Special Forces context (Bartone et al. 2008; Gruber et al. 2009). The qualitative themes (see Table 3) showed meaningful overlap with the constructs measured by means of the quantitative assessments. The themes also highlighted the importance of these aspects during selection and the roles of such coping and motivational resources in the outcome of the results. Additional themes identified can to some degree be linked to the identified framework - for example, the emphasis on religion could also serve as an example of external locus of control.

\section{Practical implications}

The contribution of this research is twofold.

Whilst no statistically significant differences were found between the selected and not-selected candidates, the quantitative results nevertheless showed that those who participated in the Special Forces screening and selection process showed a higher level of sense of coherence overall and on its sub-scales (comprehensibility, manageability and meaningfulness) compared to scores reported for other groups and the theoretical mean scores of the scales. The self-efficacy scores of the group were also higher than those reported for other groups. These elevated scores indicate that those applying for the Special Forces selection would generally seem more capable than most to cope with the physical, mental and emotional demands that they would face during selection, while undergoing training and eventually when deployed. This finding points to the possible utility of these measures by means of minimum required levels of performance - in line with the high demands of the context.

Secondly, the qualitative results aligned with the quantitative dimensions measured with themes extracted from the qualitative data clearly aligned to the quantitative framework of the different constructs. The qualitative data allowed for a glimpse into the life-world of the candidates and what they perceived as helping or hindering their success during the Special Forces selection. The qualitative data clearly supported the focus on the dimensions and sub-dimensions of sense of coherence, hardiness, locus of control and selfefficacy.

Lee et al. (2011) recommended that more research is needed to understand how psychological factors influence various outcomes in the military context. The present study provides some empirical data within the military and Special Forces selection context.

\section{Limitations of the study}

A possible contextual limitation for the study may be the prolonged preparation that all the candidates were subjected to prior to the selection process and which, to some degree, may have countered possible differences in their perceived (self-reported) view of themselves in terms of their sense of coherence, hardiness, locus of control and self-efficacy.

The parallel, mixed-method survey approach allowed for both quantitative and qualitative data to be gathered within the limited time that was available, but it precluded from the qualitative perspective any probing on an individual level to elucidate and unpack the meaning of some of the aspects mentioned. The written responses of candidates to the open-ended questions tended to be somewhat cryptic, and the resulting raw data that was available was consequently limited.

The small sample size is a further limitation, which could in time be addressed by replicating this study with other selection groups. More data from the Special Forces and the wider military context would allow for comparisons to be made in terms of the basic resilience profile of these groups.

The cross-sectional nature of the study limited results to a particular point in time whilst the responses of the candidates to the self-report measures used could have been influenced by the selection context.

\section{Recommendations}

It would be beneficial if similar groups could be assessed over time to increase the sample size and to compare the results of different selection groups. The inclusion of performance results will add further value to evaluate the predictive validity of the different measures within the Special Forces context. The assessment could also be done earlier in the process - before the preparation phase - to determine whether more distinct differences between different groups could be discerned. The high average scores on the self-report measures used could to some degree have been affected by the intensive preparation phase that preceded the selection process. This could be explored in future research.

The continued measurement of these constructs and further exploration of their potential role within the military and Special Forces contexts are recommended.

With regard to the qualitative component of the study, the use of semi-structured interviews in which some probing would be possible would improve the quality of the available data for qualitative analysis. Although focus groups may to some degree also allow for additional information to be made available, focus groups - in particular in the formal, hierarchical and structured military context - may prevent some participants from freely sharing their ideas. Individual interviews or a mixture of individual interviews and focus groups are therefore recommended as the methods to gather 
qualitative data from Special Force members or candidates during future screening and selection processes.

\section{Conclusion}

The military context will remain a demanding one and coping with the unique demands posed in this domain will remain of research interest - in particular with the aim of lowering attrition and improving selection success. As such and from the basis of this initial exploration of the role of some of the positive psychology constructs in the context of Special Forces selection, evidence was found in the alignment of qualitative data to the quantitative framework of dimensions that these factors are important in this domain.

Military-specific measures may also become available over time as it has been mentioned that, for example, militaryspecific hardiness could be a better predictor of psychological well-being in military personnel than general hardiness (Skomorovsky \& Sudom, 2011).

The role of group characteristics - such as group sense of coherence (Antonovsky \& Sourani, 1988) - could also be explored further in the Special Force context where performance as a member of a group is as important as individual performance. The effect of training on the various constructs to improve coping resources could also be explored. The recommendation of Gruber et al. (2009), that future research should continue to examine psychosocial resources and characteristics that separate successful Special Forces soldiers from unsuccessful ones, should be heeded and this initial study could serve as a starting point.

\section{Acknowledgements}

The authors wish to thank Chris Serfontein of the Special Operations Defence Evaluations and Research Institute (SODERI) and Technology for Special Operations Division of the Council for Scientific and Industrial Research (CSIR) for facilitating arrangements for assessment and funding, project stakeholder management and logistical support. Special acknowledgement and appreciation to the Special Forces of the South African National Defence Force (SANDF) for providing access to the sample used in this study and to the candidates who participated. Lastly, the authors wish to thank the anonymous reviewers for their valuable feedback which was used to revise and improve the original manuscript submitted.

\section{Competing interests}

The authors declare that they have no financial or personal relationship(s) that may have inappropriately influenced them in writing this article.

\section{Authors' contributions}

M.d.B. (University of South Africa) and A.v.H. (Council for Scientific and Industrial Research) contributed equally to the writing of this article.

\section{References}

Al-Turkait, F.A., \& Ohaeri, J.U. (2008). Prevalence and correlates of posttraumatic stress disorder among Kuwaiti military men according to level of involvement in the first Gulf war. Depression and Anxiety, 25, 932-941. http://dx.doi. org/10.1002/da.20373

Antonovsky, A. (1987). The salutogenic perspective: Toward a new view of health and illness. Advances, 4(1), 47-55.

Antonovsky, A. (1993). The implications of salutogenesis: An outsider's view. In A.P. Turnbull, J.M. Patterson, S.K. Behr, D.L. Murphy, J.G. Marquis, \& M.J. BlueBanning (Eds.), Cognitive coping, families, disability (pp. 111-112). London: Paul H. Brookes.

Antonovsky, A., \& Sourani, T. (1988). Family sense of coherence and family adaptation. Journal of Marriage and the Family, 50, 79-92. http://dx.doi.org/10.2307/352429

Bandura, A. (1982). Self-efficacy mechanism in human agency. American Psychologist, 37(2), 122-147. http://dx.doi.org/10.1037/0003-066X.37.2.122

Bandura, A. (2012). On the functional properties of perceived self-efficacy revisited. Journal of Management, 38(1), 9-44. http://dx.doi.org/10.1037/0003 066X.37.2.122

Bartone, P.T., Kelly, D.R., \& Matthews, M.D. (2013). Psychological hardiness predicts adaptability in military leaders: A prospective study. International Journal of Selection and Assessment, 21(2), 200-210. http://dx.doi.org/10.1111/ijsa.12029

Bartone, P.T., Roland, R.R., Picano, J.J., \& Williams, T.J. (2008). Psychological hardiness predicts success in US Army Special Forces candidates. International Journa of Selection and Assessment, 16(1), 78-81. http://dx.doi.org/10.1111/j.1468 2389.2008.00412.x

Bates, M.J., Bowles, S., Hammermeister, J., Stokes, C., Pinder, E., Moore, M. et al. (2010). Psychological fitness. Military Medicine, 175, 8-21. http://dx.doi. org/10.7205/MILMED-D-10-00073

Bekwa, N.N., \& De Beer, M. (2009). Salutogenic profile of police trainees on entry into the profession. Journal of Psychology in Africa, 19(2), 177-185.

Bradley, J.P., \& Nicol, A.M. (2006). Predictors of military training performance for officer cadets in the Canadian Forces. Military Psychology, 18(3), 219-226. http:// dx.doi.org/10.1207/s15327876mp1803_3

Braun, V., \& Clarke, V. (2006). Using thematic analysis in psychology. Qualitative Research in Psychology, 3(2), 77-101. http://dx.doi.org/10.1191/1478088706qp063oa

Casey, G.W. (2011). Comprehensive soldier fitness: A vision for psychological resilience in the U.S. Army. American Psychologist, 66(1), 1-3. http://dx.doi.org/10.1037/ a0021930

Chen, G., Gully, S.M., \& Eden, D. (2001). Validation of a new general selfefficacy scale. Organizational Research Methods, 4(1), 62-83. http://dx.doi. org/10.1177/109442810141004

Cilliers, F., \& Coetzee, S.C. (2003). The theoretical-empirical fit between three psychological wellness constructs: Sense of coherence, learned resourcefulness and self-actualisation. South African Journal of Labour Relations, Autumn, 4-24.

Cohen, J. (1992). A power primer. Psychological Bulletin, 12(1), 155-159. http:// dx.doi.org/10.1037/0033-2909.112.1.155

Cornum, R., Matthews, M.D., \& Seligman, M.E.P. (2011). Comprehensive soldier fitness: Building resilience in a challenging institutional context. American Psychologist, 66(1), 4-9. http://dx.doi.org/10.1037/a0021420

Creswell, J.W., \& Garrett, A.L. (2008). The movement of mixed methods research and the role of educators. South African Journal of Education, 28, 321-333.

Creswell, J.W., \& Plano Clark, V.L. (2011). Designing and conducting mixed method research. (2nd edn.). Los Angeles: Sage.

Eschleman, K.J., Bowling, N.A., \& Alarcon, G.M. (2010). A meta-analytic examination of hardiness. International Journal of Stress Management, 17(4), 277-307. http:// dx.doi.org/10.1037/a0020476

Escolas, S.M., Pits, B.L., Safer, M.A., \& Bartone, P.T. (2013). The protective value of hardiness on military posttraumatic stress symptoms. Military Psychology, 25(2), 116-123. http://dx.doi.org/10.1037/h0094953

Fetters, M.D., Curry, L.A., \& Creswell, J.W. (2013). Achieving integration in mixed methods designs: Principles and practices. Health Services Research, 48(6), 21342156. http://dx.doi.org/10.1111/1475-6773.12117

Field, A. (2009). Discovering statistics using SPSS. (3rd edn.). London: Sage Publications.

Foureur, M., Besley, K., Burton, G., Yu, N., \& Crisp, J. (2013). Enhancing the resilience of nurses and midwives: Pilot of a mindfulness-based program for increased health, nurses and midwives: Pilot of a mindfulness-based program for increased health, Nurse, 45(1), 114-125. http://dx.doi.org/10.5172/conu.2013.45.1.114

Graneheim, U.H., \& Lundman, B. (2003). Qualitative content analysis in nursing research: Concepts, procedures and measures to achieve trustworthiness. Nurse Education Today, 24, 105-112. http://dx.doi.org/10.1016/j.nedt.2003.10.001

Greenspoon, P.J., \& Saklofske, D.H. (2000). Toward an integration of subjective wellbeing and psychopathology. Social Indicators Research, 5, 81-108.

Griffiths, C.A., Ryan, P., \& Foster, J.H. (2011). Thematic analysis of Antonovsky's sense of coherence theory. Scandinavian Journal of Psychology, 52, 168-173. http:// dx.doi.org/10.1111/j.1467-9450.2010.00838.x

Gropp, L., Geldenhuys, D., \& Visser, D. (2007). Psychological wellness constructs: Relationships and group differences. South African Journal of Industrial Psychology, 33(3), 24-34.

Gruber, K.A., Kilcullen, R.N., \& Iso-Ahola, S.E. (2009). Effects of psychosocial resources on elite soldiers' completion of a demanding military selection program. Military Psychology, 21, 427-444. http://dx.doi.org/10.1080/08995600903206354 
Hobfoll, S.E., Spielberger, C.D., Breznitz, S., Figley, C., Foklman, S., Lepper-Green, B. et al. (1991). War-related stress: Addressing the stress of war and other traumatic events. American Psychologist, 46(8), 848-855. http://dx.doi.org/10.1037/0003events. American

Hochwälder, J., \& Forsell, Y. (2011). Is sense of coherence lowered by negative life events? Journal of Happiness Studies, 12, 475-492. http://dx.doi.org/10.1007/ s10902-010-9211-0

Hunt, A.P., Orr, R.M., \& Billing, D.C. (2013). Developing physical capability standards that are predictive of success on special forces selection courses. Military Medicine, 178(6), 619-624. http://dx.doi.org/10.7205/MILMED-D-12-00347

Hunter, D.R., \& Stewart, J.E. (2012). Safety locus of control and accident involvement among army aviators. The International Journal of Aviation Psychology, 22(2), 144-163. http://dx.doi.org/10.1080/10508414.2012.663244

Hystad, S.W., Eid, J., Laberg, J.C., \& Bartone, P.T. (2011). Psychological hardines predicts admission into Norwegian military officer schools. Military Psychology, 23, 381-389. http://dx.doi.org/10.1037/h0094763

Jerusalem, M. (1992). Self-efficacy as a resource factor in stress appraisal process. In R. Scwarzer (Ed.), Self-efficacy: Thought control of action (pp. 195-213). Washington, DC: Hemisphere Publishing Corporation.

Johnson, R., \& Waterfield, J. (2004). Making words count: The value of qualitative research. Physiotherapy Research International, 9(3), 121-131. http://dx.doi. org/10.1002/pri.312

Kobasa, S.C. (1979). Stressful life events, personality, and health: An inquiry into hardiness. Journal of Personality and Social Psychology, 37(1), 1-11. http://dx.doi. org/10.1037/0022-3514.37.1.1

Kobasa, S.C., Maddi, S.R., \& Kahn, S. (1982). Hardiness \& health: A prospective study Journal of Personality and Social Psychology, 42(1), 168-177. http://dx.doi. org/10.1037/0022-3514.42.1.168

Kobasa, S.C., Maddi, S.R., Pucetti, M.C., \& Zola, M.A. (1985). Effectiveness of hardiness, exercise and social support as resources against illness. Journal of Psychosomatic Research, 29(5), 525-533. http://dx.doi.org/10.1016/0022-3999(85)90086-8

Kobasa, S.C., \& Pucetti, M.C. (1983). Personality and social resources in stress resistance. Journal of Personality and Social Psychology, 45(4), 839-850. http:// dx.doi.org/10.1037/0022-3514.45.4.839

Lee, J.E.C., Sudom, K.A., \& McCreary, D.R. (2011). Higher-order model of resilience in the Canadian Forces. Canadian Journal of Behavioural Science, 43(3), 222-234. $\mathrm{http}: / / \mathrm{dx}$.doi.org/10.1037/a0024473

Luutonen, S., Sohlman, B., Salokangas, R.K.R., Lehtinen, V., \& Dowrick, C. (2011) Weak sense of coherence predicts depression: 1-year and 9-year follow-ups of the Finnish Outcomes of Depression International Network (ODIN) sample. Journal of Mental Health, 20(1), 43-51. http://dx.doi.org/10.3109/09638237.2010.537401

Maddi, S.R. (2013). Hardiness: Turning stressful circumstances into resilient growth. Irvine: Sage. http://dx.doi.org/10.1007/978-94-007-5222-1

Maddi, S.R., \& Harvey, R.H. (2006). Hardiness considered across cultures. In P.T.P. Wong, L.C.J. Wong, \& C. Scott (Eds.), Handbook of multicultural perspectives on
stress and coping (pp. 1-28). New York: Springer. http://dx.doi.org/10.1007/0stress and coping

Maddi, S.R., Matthews, M.S., Kelly, D.R., Villarreal, B., \& White, M. (2012). The role of hardiness and grit in predicting performance and retention of USMA cadets. Military Psychology, 24, 19-29. http://dx.doi.org/10.1080/08995605.2012.639672

Marais, C.P. (1997). Salutogenesis as paradigm in change management. Unpublished master's dissertation, University of South Africa, Pretoria, South Africa.

Molony, T., \& Henwood, M. (2010). Signature strengths in positive psychology. National Association of School Psychologists, 38(8), 15-16.

Rimm, H., \& Jerusalem, M. (1999). Adaptation and validation of an Estonian version of the General Self-Efficacy scale (ESES). Anxiety, Stress, and Coping, 12, 329-345. $\mathrm{http}: / / \mathrm{dx}$.doi.org/10.1080/10615809908250481

Ristkari, T., Sourander, A., Helenius, H., Nilolakaros, G., Salantera, S., Multimaki, P. et al. (2005). Sense of coherence among Finnish young men: A cross-sectional study at military call-up. Nordic Journal of Psychiatry, 59(6), 473-480. http://dx.doi. org/10.1080/08039480500360898
Rothmann, S., Jorgensen, L.I., \& Hill, C. (2011). Coping and work engagement in selected South African organisations. SA Journal of Industrial Psychology, 37(1), Art. \#962, 11 pages. http://dx.doi.org/10.4102/sajip.v37i1.962

Rotter, J. (1966). Generalized expectations for internal versus external control of reinforcements. Psychological monographs: General and Applied, 80(1), 1-28. http://dx.doi.org/10.1037/h0092976

Rotter, J. (1989). Internal versus external control of reinforcements: A case history of a variable. American Psychologist, 45(4), 489-493. http://dx.doi.org/10.1037/0003066X.45.4.489

Sarenmalm, E.K., Browall, M., Persson, L., Fall-Dickson, J., \& Gaston-Johansson, G. (2013). Relationship of sense of coherence to stressful events, coping strategies, health status, and quality of life in women with breast cancer. Psycho-Oncology, 22, 20-27. http://dx.doi.org/10.1002/pon.2053

Seligman, M.E.P., \& Fowler, R.D. (2011). Comprehensive soldier fitness and the future of psychology. American Psychologist, 66, 82-86. http://dx.doi.org/10.1037/ a0021898

Skomorovsky, A., \& Stevens, S. (2013). Testing a resilience model among Canadian forces recruits. Military Medicine, 178, 829-836. http://dx.doi.org/10.7205/ MILMED-D-12-00389

Skomorovsky, A., \& Sudom, K.A. (2011). Role of hardiness in the psychological wellbeing of Canadian forces officer candidates. Military Medicine, 176, 1-7. http:// dx.doi.org/10.7205/MILMED-D-10-00325

Stark, S., Chernyshenko, O.S., Drasgow, F., Lee, W.C., White, L.A., \& Young, M.C. (2011). Optimizing prediction of attrition with the U.S. Army's assessment of individual motivation (AIM). Military Psychology, 23, 180-201. http://dx.doi.org/10.1080/ 08995605.2011.550234

Statistics South Africa. (2012). Census 2011 - statistical release (revised) P0301.4. Pretoria: Statistics South Africa. Retrieved April 6, 2013, from http://www.statssa. gov.za

Strümpfer, D.J.W. (1990). Salutogenesis: A new paradigm. South African Journal of Psychology, 20(4), 265-276. http://dx.doi.org/10.1177/008124639002000406

Strümpfer, D.J.W. (2006). The strength perspective: Fortigenesis in adult life. Socia Indicators Research, 77, 11-36. http://dx.doi.org/10.1007/s11205-005-5551-2

Strümpfer, D.J.W., Danana, N., Gouws, J.F., \& Viviers, M.R. (1998). Personality dispositions and job satisfaction. South African Journal of Psychology, 28(2), 92100. http://dx.doi.org/10.1177/008124639802800206

Strümpfer, D.W.J., \& De Bruin, G.P. (2009). Antonovsky's sense of coherence and job satisfaction: Meta-analyses of South African data. South African Journal of Industrial Psychology, 35(1), 1-3.

Strümpfer, D.J.W., Eiselen, R.J., Meiring, D., \& Phalatse, J.S. (2010). Validating measures of psychological well-being by contrasting samples employed in hazardous and less hazardous work. Journal of Psychology in Africa, 20(1), 23-32.

Terre Blanche, M., Durrheim, K., \& Kelly, K. (2009). First steps in qualitative data analysis. In M. Terre Blanche, K. Durrheim \& D. Painter (Eds.), Research in practice (pp. 320-344). Cape Town: University of Cape Town Press.

Van der Colff, J.J., \& Rothmann, S. (2009). Occupational stress, sense of coherence, coping, burnout and work engagement of registered nurses in South Africa. South African Journal of Industrial Psychology, 35(1), 1-10.

Van Schalkwyk, L., \& Rothmann, S. (2008). Validation of the Orientation to Life Questionnaire (OLQ) in a chemical factory. South African Journal of Industria Psychology, 34(2), 31-39.

Wiese, L., Rothmann, S., \& Storm, K. (2003). Coping, stress and burnout in the South African Police Service in KwaZulu-Natal. South African Journal of Industria Psychology, 29(4), 71-80.

Wissing, M.P., \& Van Eeden, C. (2002). Empirical clarification of the nature of psychological well-being. South African Journal of Psychology, 32(1), 32-44.

Wong, T.P. (2011). Positive psychology 2.0: Towards a balanced interactive model of the good life. Canadian Psychology, 52(2), 69-81. http://dx.doi.org/10.1037/ a0022511 